\title{
BMJ Open Incidence and risk factors of retinopathy of prematurity in Korle-Bu Teaching Hospital: a baseline prospective study
}

Imoro Zeba Braimah (D) , ,2 Christabel Enweronu-Laryea, ${ }^{3,4}$ Adziri Harold Sackey, ${ }^{3,4}$ Ernest Kenu, ${ }^{5}$ Kofi Agyabeng, ${ }^{6}$ Imelda-Odille Dziffa-Bella Ofori-Adjei, ${ }^{2}$ Vera Beyuo, ${ }^{2}$ Aaron Oku, ${ }^{2}$ Vera Adobea Essuman ${ }^{1,2}$

To cite: Braimah IZ, EnweronuLaryea C, Sackey AH, et al. Incidence and risk factors of retinopathy of prematurity in Korle-Bu Teaching Hospital: a baseline prospective study. BMJ Open 2020;10:e035341. doi:10.1136/ bmjopen-2019-035341

- Prepublication history and additional material for this paper are available online. To view these files, please visit the journal online (http://dx.doi org/10.1136/bmjopen-2019035341).

Received 28 0ctober 2019 Revised 15 June 2020 Accepted 25 June 2020

\section{Check for updates}

(C) Author(s) (or their employer(s)) 2020. Re-use permitted under CC BY-NC. No commercial re-use. See rights and permissions. Published by BMJ.

For numbered affiliations see end of article.

Correspondence to Dr Vera Adobea Essuman; vaessuman@ug.edu.gh

\section{ABSTRACT}

Objective To determine the incidence of retinopathy of prematurity (ROP) and any associated risk factors among preterm infants at the Neonatal Intensive Care Unit (NICU) of Korle-Bu Teaching Hospital (KBTH).

Design Prospective study.

Setting Level 3 NICU of KBTH from June 2018 to February 2019.

Participants Eligible infants with birth weight (BW) less than $2 \mathrm{~kg}$ or gestational age (GA) less than 37 weeks were examined at scheduled intervals until full maturity of their retina.

Outcome measures The primary outcome measure was cumulative incidence of ROP and secondary outcome measure was risk factors associated with ROP.

Results Of the 401 infants, 222 were females (55.4\%), mean \pm SD GA was $32.3 \pm 2.4$ weeks (median 32, IQR 31 to 34 ) and mean BW $1.6 \pm 0.4 \mathrm{~kg}$ (median 1.5, IQR 1.3 to 1.9). The cumulative incidence of ROP was $13.7 \%(95 \%$ Cl: 10.5 to $17.5 \%$ ), with $1.8 \%$ (seven infants) having type 1 ROP. Increased risk of ROP was observed in babies with supplemental oxygen exposure $(p<0.001)$, BW less than $1.5 \mathrm{~kg}(p=0.019)$, confirmed neonatal sepsis $(p=0.001)$, nasogastric tube feeding $(p=0.03)$ and poor pupillary dilation (0.032). A reduced risk of ROP was observed in boys $(p=0.004)$ and after delivery by caesarean section $(p=0.019)$.

Conclusion The rates of ROP at KBTH are comparable to other NICUs in sub-Saharan Africa. Birth weight less than $1.5 \mathrm{~kg}$, confirmed neonatal sepsis, nasogastric tube feeding and poor pupil dilation were independently associated with increased incidence of ROP. ROP screening should be a part of the routine service for premature infants in Ghana.

\section{INTRODUCTION}

Retinopathy of prematurity (ROP) is a vascular disorder of the immature retina. It is the leading cause of childhood blindness in high-income countries. ${ }^{12}$ In low- and middleincome countries (LMICs), ROP is becoming an important cause of childhood blindness due to increasing survival associated with access to neonatal intensive care services. ${ }^{1}$ The burden of visual impairment or blindness

\section{Strengths and limitations of this study}

To date, this is the largest prospective study on retinopathy of prematurity (ROP) in West Africa.

- Our study adopted a broader ROP screening criteria of birth weight $<2 \mathrm{~kg}$ and $/$ or gestational age $<37$ weeks.

- Our findings has contributed to the gap in literature on independent factors associated with increased risk of ROP in sub-Saharan Africa.

- This study was conducted in a level 3 neonatal intensive care unit (NICU) and hence not representative of all NICUs in Ghana.

- About $4 \%$ of babies did not complete all screening eye examinations.

from ROP can be reduced by improving the quality of obstetric and neonatal care, early detection through screening and by appropriate treatment of type $1 \mathrm{ROP}^{3-9}$

There are several risk factors for ROP including, prematurity, very low birth weight (VLBW), supplemental oxygen exposure, respiratory distress syndrome, sepsis, multiple blood transfusion, mechanical ventilation and male sex. ${ }^{10-14}$ In high-income countries, ROP usually occurs in infants with birth weight (BW) $<1.5 \mathrm{~kg}$ or gestational age (GA) $<32$ weeks. ${ }^{1}$ However, ROP has been reported in preterm infants with $\mathrm{BW}>1.5 \mathrm{~kg}$ and GA of 32 to 36 weeks in LMIC, probably due to lower quality care. ${ }^{1215}$ ROP was previously thought not to be a problem in sub-Saharan Africa (SSA) due to the poor survival of preterm infants. $^{2}$

Ghana is a lower middle-income country with neonatal mortality rate (NMR) of 28 per 1000 live births compared with NMR of 3.0 per 1000 live births in high-income countries. ${ }^{16} 17$ The incidence of ROP in Ghana is unknown but access to neonatal intensive care services is improving and more preterm infants are surviving. ${ }^{18} 19$ The refurbishment 
of the Neonatal Intensive Care Unit (NICU) of Korle-Bu Teaching Hospital (KBTH) led to an improvement in survival of babies with birth weight $<2.5 \mathrm{~kg}$ from $67.4 \%$ to $78.2 \% .{ }^{18}$ A recent study of mortality rate over a 5 -year period at the NICU of KBTH found gestational specific mortality rate in preterm babies was $25.8 \% .{ }^{19}$ ROP may become a significant cause of visual impairment as the established risk factors are commonly seen in NICUs in Ghana. The population of infants at risk may be different in Ghana as evidenced by the existence of ROP in bigger, more mature infants in LMIC. ${ }^{1{ }^{15}}$ In this study, we assessed the risk factors for ROP and examined hospitalised infants to establish the criteria for screening infants at KBTH, Accra, the largest hospital in Ghana.

\section{METHODS}

This prospective study was conducted at the NICU of KBTH from June 2018 to February 2019. The NICU admits about 2500 infants annually and about $55 \%$ of these are preterm/low birth weight. Gestational age is usually determined by the attending obstetrician. Where records of GA was not available, it was determined by paediatric residents using the Ballard score. ${ }^{20}$ There is a post-discharge follow-up outpatient service for infants admitted to NICU and the hospital has a paediatric ophthalmology and retina service.

All infants who met the eligible criteria (GA $<37$ weeks and/or BW $<2 \mathrm{~kg}$ ) were enrolled after obtaining informed consent from parents. Infants with severe congenital nonocular anomalies or severe congenital ocular anomalies in one or both eyes were excluded.

A pretested questionnaire (online supplementary appendix 1) was used to obtain antenatal, perinatal and postnatal data from parents and medical records. Eye examination commenced at 3 weeks postnatal age in the NICU or postnatal clinic for infants discharged earlier. The pupils were dilated with $0.5 \%$ tropicamide and $2.5 \%$ phenylephrine (instilled three times at $10 \mathrm{~min}$ interval) prior to eye examination. In babies with poor pupillary dilation, the instillation of the eye drops was repeated on the same day by the examining ophthalmologist and the eyes examined after $30 \mathrm{~min}$. The anterior segment and retinal examination including indirect ophthalmoscope (Keeler, UK) and 20D Volk lens with scleral indentation were performed by the retina specialist (IZB) and two paediatric ophthalmologists (VAE and I-OD-BO-A). For quality assurance, inter-observer agreement was established before commencement of the study.

Eye examination was repeated at two weekly intervals until ROP or full vascularisation of retina (retinal vessels at or within one disc diameter of the temporal ora serrata) was observed. Data on eye examinations were recorded according to the zone, highest stage of ROP, extent of disease (clock hours) and presence of plus disease using the International Classification of ROP revisited scheme. ${ }^{21}$ Diagnosis of type 1 ROP was made if any of the following criteria were met: (a) zone 1, any stage ROP with plus disease; (b) zone 1, stage 3, with or without plus disease and (c) zone 2, stage 2 or 3 ROP, with plus disease..$^{21}$ After obtaining separate informed consent from their parents, infants with type 1 ROP were treated with near-confluent laser photocoagulation using $810 \mathrm{~nm}$ diode laser (Iridex, USA) to areas of avascular peripheral retina up to the ora serrata. The laser treatment was performed (IZB) within 48 hours of detection of type 1 ROP.

\section{Patients and public involvement}

The parents of the infants and the public were not involved in the design or conduct of this study. The findings from this study will be disseminated to the public through lectures, presentation at conferences and publications.

\section{Statistical analysis}

Assuming incidence of ROP at GA 32 to 36 weeks was 7.7\%, at $95 \% \mathrm{CI}$ and power of $80 \%$, the minimum cohort required was 346 . The primary outcome measure was cumulative incidence of ROP and secondary outcome measure was risk factors associated with ROP.

Microsoft Office Excel was used for data entry and analysis was done with Stata V.14.1. Cumulative incidence of ROP and $95 \%$ CI estimated by the binomial exact method was defined as the proportion of babies clinically diagnosed with ROP by the end of study period. Incidence rate was defined as the ratio of the total number of clinical ROP cases to the total child weeks at risk. This was expressed per 1000 child weeks at risk. Relative risk was also computed as the ratio of the incident rate of exposed category to the incident rate of unexposed category. The log-rank test was used in testing for the equality of the survival function between the exposure levels of the independent variables. $\chi^{2} /$ Fisher's exact test of independence was used in testing for association between the cumulative incidence of ROP and the independent variables. The Cox proportional hazards model was used in determining the effect of selected characteristics of the babies on their hazard (or risk) of developing ROP within the given study time period. Poisson regression model was used as a sensitive analysis. In testing for the proportionality assumption $(\mathrm{PH})$ under the standard Cox model, the Schoenfeld residual test and the graphical approach were used. All statistical tests were done at $5 \%$ level of significance.

The study was performed in accordance with the tenets of Declaration of Helsinki on human subjects.

We used the STROBE cross-sectional reporting guidelines for reporting observational studies (von Elm E, Altman DG, Egger M, Pocock SJ, Gotzsche PC, Vandenbroucke JP. The Strengthening the Reporting of Observational Studies in Epidemiology (STROBE) Statement: guidelines for reporting observational studies.)

\section{RESULTS}

Of the 1544 infants admitted to the NICU over the 8 months study period, $688(44.6 \%)$ met the inclusion criteria, 157 $(22.8 \%)$ died and 2 were transferred out before their first eye examination. Of the remaining 529 babies, 106 (20\%) 


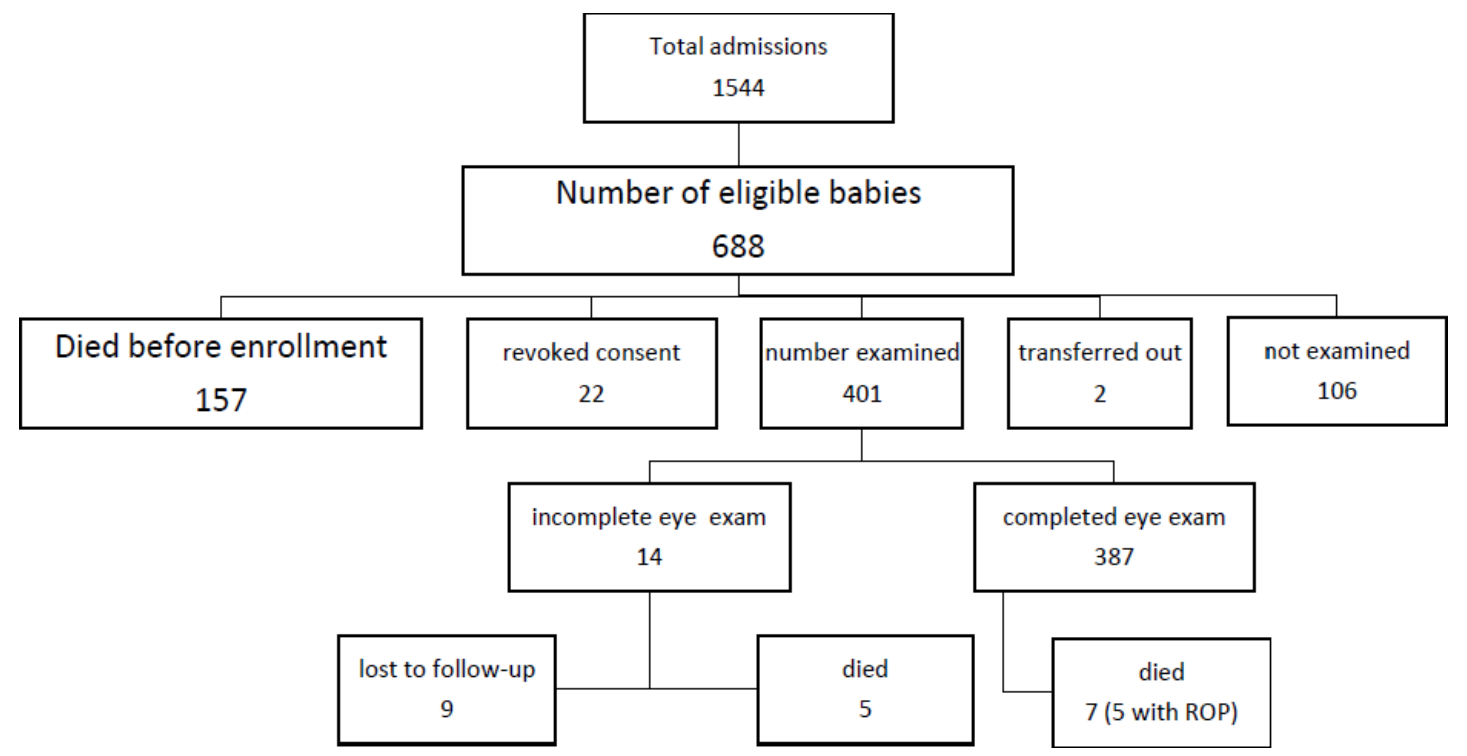

Figure 1 Diagram showing the flow of participants through the study. ROP, retinopathy of prematurity.

were discharged without referral to the study team for eye examination, $22(4.2 \%)$ infants could not be examined because parents refused consent for eye examination (despite prior informed consent at recruitment). The remaining $401(75.80 \%)$ had at least one eye examination, 12 infants died before discharge. The overall mortality rate of this cohort was $24.6 \%(169 / 688)$. The mortality rate among male infants was $30.4 \%(106 / 348)$ while in female infants was $18.5 \%$ (63/340) (Fisher's exact test $p$ value $=0.0046$ ). Figure 1 provides the flow of participants through the study.

\section{Baseline characteristics of study participants}

Overall, $222(55.4 \%)$ of examined infants were females. The mean GA was 32.3 \pm 2.4 weeks (median 32, IQR 31 to 34 ) and mean $\mathrm{BW} 1.6 \pm 0.4 \mathrm{~kg}$ (median 1.5, IQR 1.3 to 1.9). Mean length of stay (LOS) was $20.9 \pm 15.1$ days (median 17, IQR 9 to 29). The mean post menstrual age at first eye examination was $35.1 \pm 2.6$ weeks (IQR 33 to 37 ). The mean number of eye examinations was $1.5 \pm 0.7$ (median 1, IQR 1 to 2). Of 401 infants examined, 247 $(61.6 \%)$ required only one screening examination. The total number of screening examinations was 588, and 14 $(3.5 \%)$ infants did not complete screening examinations.

The prevalence of confirmed sepsis was $18.5 \%$ (74/401); $294(73.3 \%)$ infants had neonatal jaundice requiring phototherapy; 144 (35.9\%) were fed via nasogastric tube; $95(23.7 \%)$ had LOS $>28$ days; $232(57.9 \%)$ respiratory distress syndrome, $36(9.0 \%)$ received blood transfusion; $311(77.6 \%)$ were singleton and $321(80.1 \%)$ were delivered in KBTH (table 1). Poor pupil dilation occurred in $3.2 \%(13 / 401)$ infants; $10(2.5 \%)$ had persistent tunica vasculosa lentis, $1(0.3 \%)$ had anterior pyramidal cataract and $1(0.3 \%)$ had corneal opacity. The corneal opacity did not impede fundus examination.

The mean maternal age was $30.6 \pm 6.5$ years and the underlying cause of preterm delivery were pre-eclampsia $137(34.2 \%)$, premature rupture of membranes 166
$(41.4 \%)$ and antepartum haemorrhage $23(5.7 \%)$. Historical data on antenatal steroid for premature labour was available for 186 mothers, and $136(73.1 \%)$ received at least one dose of dexamethasone.

\section{Incidence of ROP and associated factors}

Fifty-five (13.7\%) infants had ROP. Among infants diagnosed with any type of ROP, the median GA at birth was 29 weeks (IQR 28 to 31), and the median post-menstrual age was 34 weeks (IQR 33 to 35 ). One infant had zone 2 stage 1 no plus ROP at GA greater than 32 weeks. This infant was born at GA of 34 weeks, was small for gestational age, had respiratory distress, congenital heart disease, confirmed neonatal sepsis and received blood transfusion during 57 days hospitalisation. All babies with ROP had BW $<1.5 \mathrm{~kg}$ except one female infant of a mother with gestational diabetes mellitus who had BW $1.59 \mathrm{~kg}$ at GA 31 weeks; she had respiratory distress syndrome and poor weight gain. Of the five babies with ROP who died, four of them had zone 2 stage 1 no plus ROP and the fifth baby had zone 1 stage 2 ROP with plus disease (figure 1 ).

The incidence of retinopathy of prematurity and background characteristics of study participants is reported in table 1. The cumulative incidence (CI) of ROP among the infants was $13.7 \%$ (95\% CI: $10.5 \%$ to $17.5 \%$ ) and the incidence rate per 1000 child-weeks at risk was $3.8(95 \%$ CI: 2.9 to 4.9$)$. Of the screened infants, $156(38.9 \%)$ had GA $<32$ weeks and $179(44.4 \%)$ had BW $<1.5 \mathrm{~kg}$. Infants with GA $<32$ weeks had significantly higher cumulative incidence of ROP $\left(\chi^{2}=72.5, p<0.001\right)$. Infants with BW $<1.5 \mathrm{~kg}$ were significantly, about 30 times, more likely to have ROP than those with BW of $1.5 \mathrm{~kg}$ or higher (Fisher's exact test $p$ value $<0.001)$. LOS $>4$ weeks was significantly associated with ROP $\left(\chi^{2}=97.8, p<0.001\right)$. Twelve $(92.3 \%)$ of babies with poor pupillary dilation had ROP. Infants with poor pupillary dilation were about eight times more likely to have ROP than those with normal pupillary dilation $\left(\chi^{2}=70.1, p<0.001\right)$. 


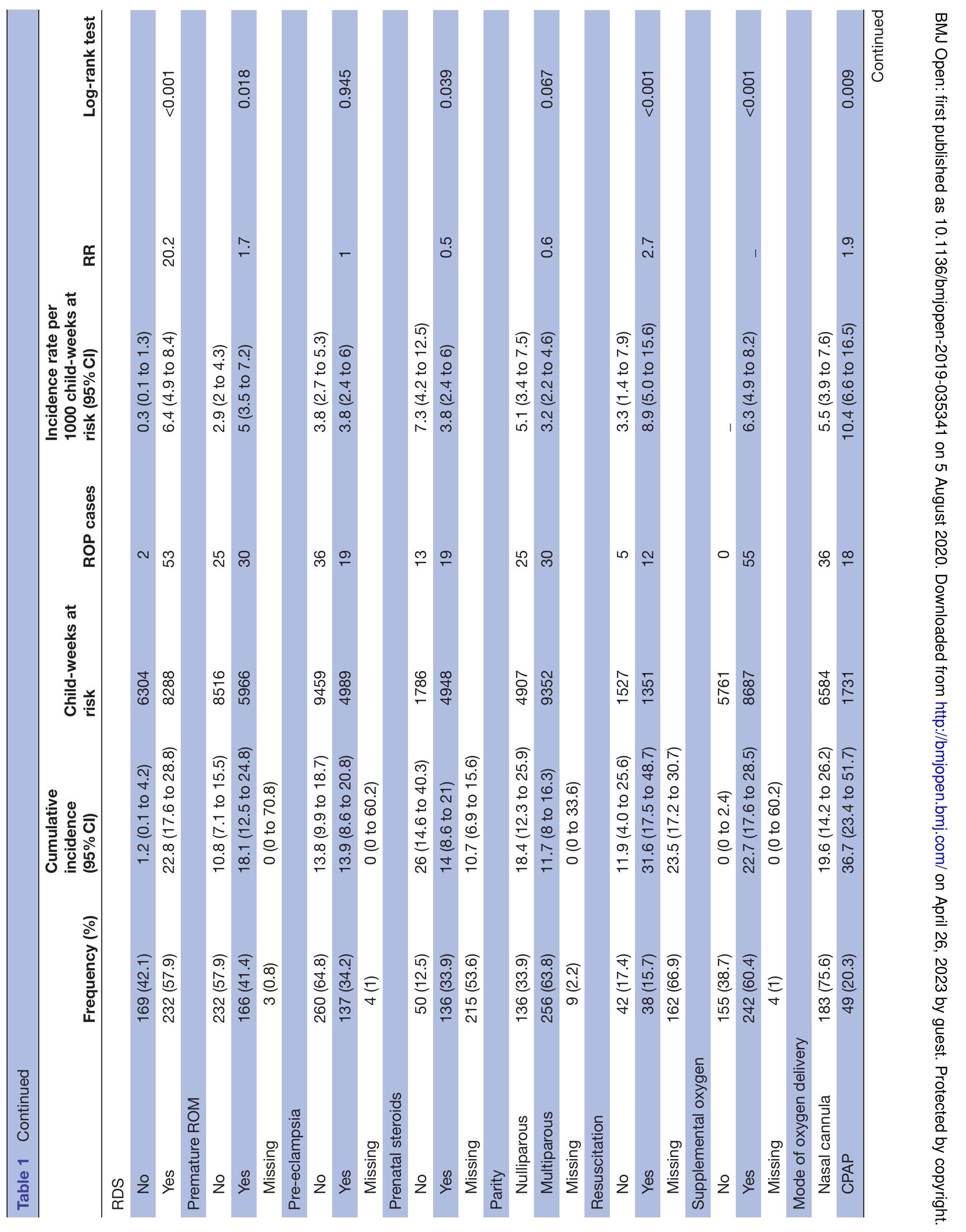




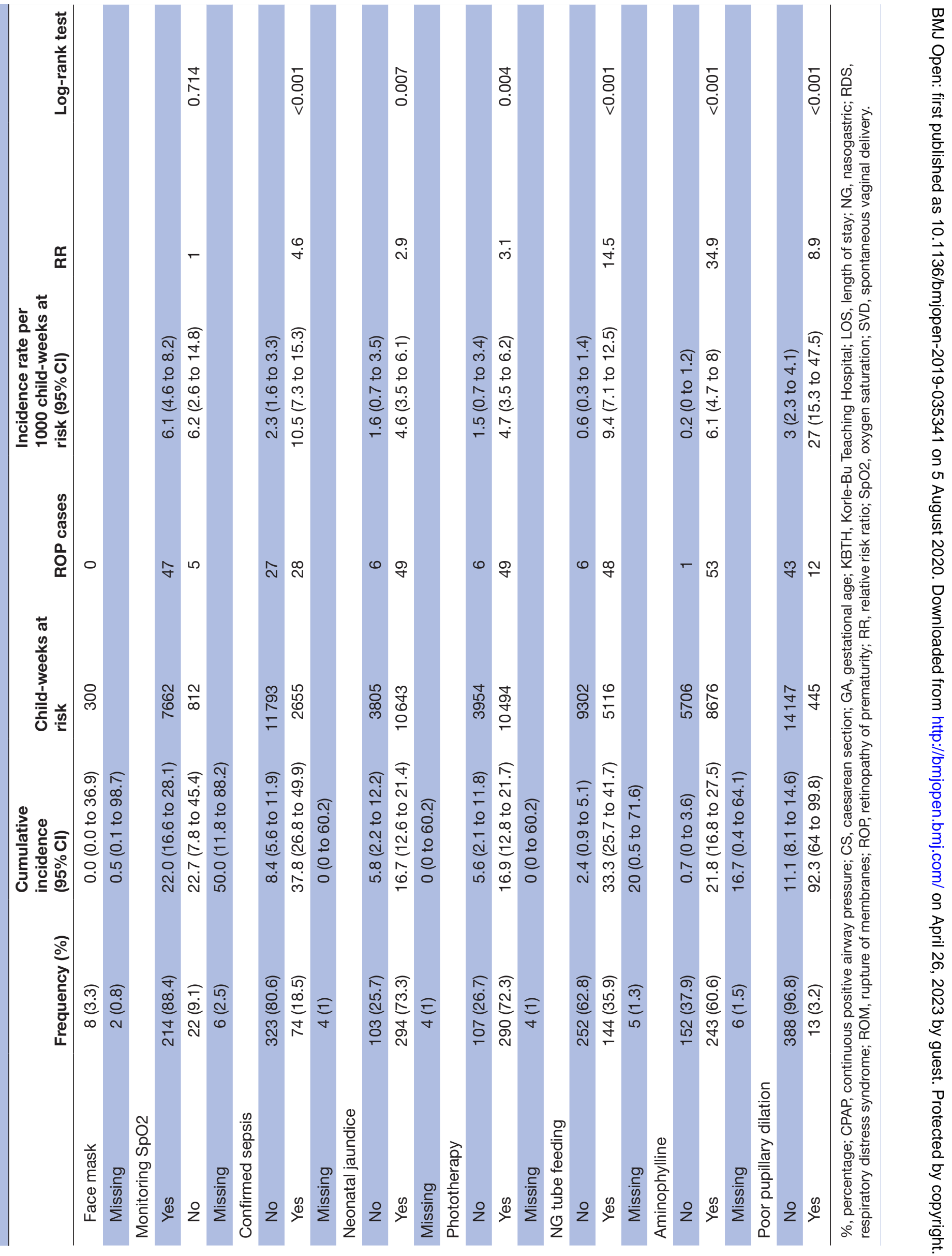


Table 2 Frequency of any ROP and type 1 ROP versus gestational age and birth weight

\begin{tabular}{|c|c|c|c|}
\hline & Number (\%) & Any ROP (\%) & $\begin{array}{l}\text { Type } 1 \\
\text { ROP (\%) }\end{array}$ \\
\hline \multicolumn{4}{|c|}{ Gestational age (weeks) } \\
\hline 27 & $8(2.0)$ & 7/8 (87.55) & $1 / 8(12.5)$ \\
\hline 28 & $20(5.0)$ & $11 / 20(55.0)$ & $\begin{array}{l}2 / 20 \\
(10.0)\end{array}$ \\
\hline 29 & $31(7.7)$ & $11 / 31(35.5)$ & 1/32 (3.1) \\
\hline 30 & $41(10.2)$ & 9/41 (22) & $1 / 41(2.4)$ \\
\hline 31 & $56(14.0)$ & $12 / 56((21.4)$ & 2/56 (3.6) \\
\hline 32 & $46(11.5)$ & $4 / 46(8.7)$ & \\
\hline 33 & $61(15.2)$ & 0 & \\
\hline 34 & $52(13.0)$ & $1(1.9)$ & \\
\hline 35 & $54(13.5)$ & 0 & \\
\hline 36 & $31(7.7)$ & 0 & \\
\hline 37 & 0 & 0 & \\
\hline 38 & $1(0.3)$ & 0 & \\
\hline Total & $400(100)$ & $55(13.7)$ & $7(1.8)$ \\
\hline \multicolumn{4}{|l|}{ Birth weight (kg) } \\
\hline $0.750-1.000$ & $20(5.0)$ & $12 / 20(60)$ & $2 / 20(10)$ \\
\hline $1.001-1.250$ & $70(17.5)$ & $31 / 70(44.3)$ & $5 / 70(7.1)$ \\
\hline $1.251-1.500$ & $96(23.9)$ & $11 / 96(11.4)$ & 0 \\
\hline $1.501-1.750$ & 78 (19.4) & $1 / 78(1.3)$ & 0 \\
\hline$>1.750$ & $137(34.2)$ & 0 & 0 \\
\hline Total & $401(100)$ & 55 (13.7) & $7(1.8)$ \\
\hline
\end{tabular}

ROP, retinopathy of prematurity.

\section{Frequency of type 1 ROP}

The relationship between the frequency of ROP versus gestational age and birth weight are summarised in table 2. Seven (1.8\%) infants developed type 1 ROP and six were treated with diode laser photocoagulation. The seventh infant died within 24 hours of diagnosis. Among infants with type 1 ROP, median GA was 29 weeks (IQR 28 to 30.5 ), median BW was $1.1 \mathrm{~kg}$ (IQR 1.0 to 1.1 ) and median postmenstrual age was 34 weeks (IQR 33 to 34.5 ). Six (46.2\%) of the babies with poor pupillary dilation had type 1 ROP. The cumulative incidence of type $1 \mathrm{ROP}$ in the group with ROP was $12.7 \%$ (95\% CI: $5.3 \%$ to $25.5 \%$ ). The cumulative incidence of type 1 ROP was significantly higher among children who had poor pupillary dilation $(50.0 \%$ vs $2.3 \%$, Fishers' exact $\mathrm{p}-$ value $<0.001)$

\section{Determinants of risk of developing ROP}

Table 3 presents details of the results on test of proportionality hazard assumption for the independent variables together with the global test for both before and after stratification approach. From the tests, with the exception of GA $<32$ weeks, all the other variables satisfied the assumption for the proportional hazards model. Since GA $<32$ weeks was significant but violated the assumption, it could not be discarded from the model. However, to control for it, the stratification approach was used.

From the multiple cox proportional hazard model (table 4), BW $<1.5 \mathrm{~kg}$, vaginal delivery, confirmed sepsis status, NG tube feeding and poor pupillary dilation status were significantly predictive of the risk of any ROP. The hazard of developing ROP among babies with BW $<1.5 \mathrm{~kg}$ was about 11 times that of babies with greater birth weights (adjusted HR (aHR): 11.7, 95\% CI: 1.5 to 91.6). However this effect should be treated with caution because of the wide CI. Male babies (aHR: 0.4, 95\% CI: 0.2 to 0.7 ) as well as babies delivered by caesarean section (aHR: 0.3, 95\% CI: 0.1 to 0.8 ) had a reduced risk of developing ROP compared with female babies and those delivered vaginally, respectively.

\section{DISCUSSION}

This study has established the occurrence of ROP in preterm infants admitted to a NICU in Accra, Ghana. We have also determined the incidence and risk factors for ROP in this cohort with a cumulative incidence of $13.7 \%$ and 3.8 incidence rate per 1000 child-weeks at risk. Published work from West Africa did not report the incidence rate, and ROP screening was restricted to babies with BW $\leq 1.5 \mathrm{~kg}$ and GA $<32$ weeks. ${ }^{22-24}$ The finding of ROP in one infant with $\mathrm{BW}>1.5 \mathrm{~kg}$ and GA $>32$ weeks in this cohort corroborates reports from middle-income countries. ${ }^{25-27}$ We however did not find type 1 ROP among infants with GA $>32$ weeks or BW $>1.25 \mathrm{~kg}$, a finding similarly reported by Mayet and Cockinos in South Africa and Freitas et al in Brazil. ${ }^{28}{ }^{29}$ Zin et al reported that, in NICUs with high survival rates $(>80 \%)$, all infants needing treatment had $\mathrm{BW}<1.5 \mathrm{~kg}$ or GA $<32$ weeks. ${ }^{27}$ They suggested that survival rates for infants with $\mathrm{BW} \leq 1.5 \mathrm{~kg}$ may predict babies at risk of ROP needing treatment. ${ }^{27}$ The incidence of ROP in Nigeria was reported to be very low over a decade ago. ${ }^{22}{ }^{23}$ The low rate of ROP was attributed to high infant mortality rate in West Africa, and that blindness from ROP was not a problem in SSA because premature infants did not survive long enough to develop severe ROP. ${ }^{2}$ The incidence of ROP was however found to be higher in South Africa and Kenya. ${ }^{28}{ }^{30}$ There are recent reports of increasing incidence of ROP in $\mathrm{SSA}^{24} 3132$ and this can be attributed to the decline in neonatal mortality rate associated with expansion in neonatal and special care baby units but with inadequate human resource and unmonitored oxygen use. ${ }^{16} 183$ The low cumulative incidence of ROP (13.7\%) in our study was due to the adoption of a wide screening criteria of $\mathrm{BW}<2 \mathrm{~kg}$ or $\mathrm{GA}<37$ weeks. Fifty $(30.3 \%)$ of the babies with $\mathrm{BW}<1.5 \mathrm{~kg}$, and $54(32.1 \%)$ of babies with GA $<32$ weeks developed ROP in our study.

The incidence of type 1 ROP $(1.8 \%)$ in our study is consistent with previous reports of low incidence of type 1 ROP worldwide. ${ }^{1} 1034$ Screening for ROP is advocated because premature babies with type 1 ROP are at a high risk of blindness and the associated effects of 
Table 3 Test of proportionality assumption

\begin{tabular}{|c|c|c|c|c|}
\hline & \multicolumn{2}{|c|}{ Before stratification } & \multicolumn{2}{|c|}{ After stratification } \\
\hline & $\chi^{2}$ & Prob $>\chi^{2}$ & $\chi^{2}$ & Prob $>\chi^{2}$ \\
\hline Length of admission $>4$ weeks: yes & 1.68 & 0.1948 & 1.37 & 0.242 \\
\hline GA $<32$ weeks: yes & 6.4 & 0.0114 & & \\
\hline Sex: male & 3.34 & 0.0677 & 3.13 & 0.0767 \\
\hline Birth weight less than $1.5 \mathrm{~kg}$ : yes & 0.96 & 0.3284 & 0.86 & 0.3538 \\
\hline Delivered at KBTH: yes & 0.49 & 0.486 & 0.69 & 0.4061 \\
\hline Mode of delivery: CS & 0.19 & 0.6634 & 0.26 & 0.612 \\
\hline Transfusion: yes & 0.02 & 0.8831 & 0.02 & 0.8767 \\
\hline Cardiac abnormalities: yes & 1.05 & 0.3055 & 1.34 & 0.2466 \\
\hline RDS: yes & 1.22 & 0.2697 & 1.51 & 0.2184 \\
\hline Premature ROM: yes & 0 & 0.9728 & 0 & 0.9523 \\
\hline Confirmed sepsis: yes & 2.07 & 0.15 & 1.8 & 0.1793 \\
\hline Neonatal Jaundice: yes & 1.23 & 0.2672 & 1.4 & 0.2375 \\
\hline Tube feeding: yes & 1.99 & 0.1586 & 1.59 & 0.2071 \\
\hline Bronchodilator - aminophylline: yes & 2 & 0.1572 & 2.01 & 0.1563 \\
\hline Poor pupillary dilation: yes & 2.83 & 0.0927 & 3.01 & 0.0829 \\
\hline Global test & 27.3 & 0.0264 & 23.6 & 0.0512 \\
\hline
\end{tabular}

CS, caesarean section; GA, gestational age; KBTH, Korle-Bu Teaching Hospital; RDS, respiratory distress syndrome; ROM, rupture of membranes.

lifelong blindness. ${ }^{125}$ Guidelines for ROP screening vary according to socioeconomic status with LMIC adopting broader screening criteria compared with high-income countries. The American Academy of Pediatrics, American Academy of Ophthalmology and other professional bodies in the USA recommend screening of all babies with
BW $\leq 1500$ g or GA $\leq 30$ weeks and selected infants with BW between 1500 and $2000 \mathrm{~g}$ or GA of $>30$ weeks who are believed by their attending paediatrician or neonatologist to be at risk for ROP. ${ }^{35}$ The UK retinopathy of prematurity guidelines recommends that, babies with $\mathrm{BW}<1501 \mathrm{~g}$ or GA $<32$ weeks should be screened for ROP. ${ }^{36}$ While

Table 4 Effects of selected characteristics on incidence of ROP among babies at KBTH

\begin{tabular}{|c|c|c|c|c|c|c|}
\hline & \multicolumn{3}{|c|}{ Cox model } & \multicolumn{3}{|c|}{ Poisson model } \\
\hline & aHR & $95 \% \mathrm{Cl}$ & $P$ value & aRR & $95 \% \mathrm{Cl}$ & $P$ value \\
\hline Length of admission $>4$ weeks: yes & 2 & 0.97 to 4.12 & 0.06 & 1.93 & 0.93 to 4.00 & 0.077 \\
\hline Sex: male & 0.37 & 0.19 to 0.74 & 0.004 & 0.52 & 0.28 to 0.97 & 0.04 \\
\hline Birth weight less than $1.5 \mathrm{~kg}$ : yes & 11.66 & 1.49 to 91.62 & 0.019 & 12.17 & 1.53 to 96.60 & 0.018 \\
\hline Delivered at KBTH: yes & 1.25 & 0.57 to 2.73 & 0.579 & 1.37 & 0.64 to 2.92 & 0.421 \\
\hline Mode of delivery: CS & 0.31 & 0.12 to 0.83 & 0.019 & 0.35 & 0.14 to 0.91 & 0.032 \\
\hline Transfusion: yes & 1.05 & 0.53 to 2.08 & 0.886 & 1.33 & 0.68 to 2.58 & 0.405 \\
\hline Cardiac abnormalities: yes & 1.78 & 0.66 to 4.75 & 0.253 & 0.93 & 0.37 to 2.34 & 0.875 \\
\hline RDS: yes & 2.68 & 0.58 to 12.45 & 0.208 & 3.01 & 0.66 to 13.76 & 0.156 \\
\hline Premature ROM: yes & 0.7 & 0.26 to 1.89 & 0.478 & 0.63 & 0.24 to 1.64 & 0.346 \\
\hline Confirmed sepsis: yes & 2.72 & 1.47 to 5.04 & 0.001 & 2.01 & 1.11 to 3.65 & 0.022 \\
\hline Neonatal jaundice: yes & 1.23 & 0.48 to 3.10 & 0.667 & 1.17 & 0.47 to 2.90 & 0.73 \\
\hline NG tube feeding: yes & 2.8 & 1.10 to 7.10 & 0.03 & 2.2 & 0.85 to 5.70 & 0.105 \\
\hline Aminophylline use: yes & 2.2 & 0.25 to 19.62 & 0.48 & 1.92 & 0.22 to 17.09 & 0.559 \\
\hline Poor pupillary dilation: yes & 2.28 & 1.08 to 4.82 & 0.032 & 2.09 & 1.03 to 4.26 & 0.041 \\
\hline
\end{tabular}

aHR, adjusted HR; aRR, adjusted relative risk; CS, caesarean section; KBTH, Korle-Bu Teaching Hospital; NG, nasogastric tube; RDS, respiratory distress syndrome; ROP, retinopathy of prematurity. 
only one baby with ROP would have been missed in our study using BW $\leq 1500 \mathrm{~g}$ criteria, $17(30.9 \%)$ and $5(9.1 \%)$ of babies with ROP would have been missed using GA $\leq 30$ weeks and GA $<32$ weeks, respectively. This latter findings of ROP in more mature babies than in the USA or UK is consistent with other reports in LMIC. ${ }^{25-27}$ The KBTH is a level 3A high volume unit with insufficient staff especially neonatologist and neonatal nurses, and limited number of equipment especially pulse oximeters for monitoring oxygen saturation. Administered oxygen to VLBW babies is largely unblended with blending restricted to babies on continuous positive airway pressure who are been weaned off oxygen. Continuous monitoring of oxygen is lacking and oxygen saturation is often measured in very ill babies with unstable clinical course. The level of neonatal care is therefore suboptimal compared with the USA or UK. As the largest tertiary hospital, the level of neonatal care in KBTH is expected to be higher than other NICUs and special care baby units in Ghana. Our findings may not be representative of other NICUs and special care baby units because of variations in the level and quality of neonatal care. ${ }^{27} 29$ Our proposed screening criteria for Ghana are birth weight less than $1.6 \mathrm{~kg}$ or gestational age less than or equal to 34 weeks. These criteria should be reviewed when additional data from other NICUs and special care baby units become available in the future.

Our finding of VLBW, confirmed sepsis and exposure to supplemental oxygen as independent risk factors for ROP is supported by previous published reports. ${ }^{5-10} \mathrm{~A}$ prospective study in Egypt found sepsis as independent risk factor for ROP. ${ }^{34}$ The rate of sepsis in this Egyptian study was high; $92.3 \%$ in the babies with ROP and $47 \%$ in those without ROP. ${ }^{34}$ A prospective study in the Netherlands found lower rate of sepsis; $31.7 \%$ in babies with ROP and $17.8 \%$ among those without ROP. ${ }^{37}$ The rate of sepsis in a large nationwide cohort of preterm babies in the USA with hospital LOS $>28$ days was $41.4 \%$ for the babies with ROP and $39.0 \%$ in the babies without ROP. ${ }^{38}$ In our study, confirmed sepsis was found in $50.9 \%$ of the babies who developed ROP and in $13.3 \%$ without ROP. Although the rate of sepsis in babies with ROP appear to be higher in our study compared with the Netherlands and USA, direct comparison cannot be made due to differences in screening criteria, level of prematurity and birth weight. The number of days of oxygen exposure was the only independent risk factor for ROP in a prospective study by Wanjala et al in Kenya. ${ }^{30}$ Other studies on risk factors of ROP in SSA reported on univariate analysis without performing multiple logistic regression analysis and hence their findings may be limited by confounding factors. ${ }^{23} 243239$

A number of studies have observed that male sex was a significant risk factor for ROP ${ }^{3740}$ Other studies found female sex as an independent risk factor for ROP. ${ }^{38} 42$ Shim et al found female sex as an independent risk factor for severe ROP in babies with GA $>25$ weeks. ${ }^{42}$ In our cohort, all babies below 27 weeks gestation died before they were due for eye examination. Our findings of higher risk of ROP $(\mathrm{p}=0.004)$ in females with 27 weeks of gestation or greater compared with males is therefore in agreement with similar observation by Shim et al. ${ }^{42}$ The observation that the mortality rate among males was significantly higher compared with females in our current study corroborate findings from previous studies. ${ }^{42-44}$ Our finding that male sex was independently associated with reduced risk of ROP may also be due to the fact that extremely premature male infants did not survive long enough to develop ROP.

Feeding through NG tube was also an independent risk factor for ROP in our study. Tube feeding is generally required for neonates with poor suck, swallow or respiratory coordination due to illness or prematurity, especially before 33 to 36 weeks post-conceptional age. ${ }^{45}$ The need for tube feeding should therefore correlate well with gestation, severity of illness and with occurrence of ROP. ${ }^{1125}$ The presence of poor pupillary dilation was an independent risk factor for type 1 ROP in our study. Other ocular features found in the babies with poor pupillary dilation were corneal haze, persistent tunica vasculosa lentis and engorged iris vessels all of which are features associated with severe ROP. ${ }^{715} \mathrm{Six}(85.7 \%)$ of the babies with type 1 ROP in this study had poor pupillary dilation at the first screening examination. Poor pupillary dilation may be a result of improper instillation of eye drops, although the neonatal/ophthalmic nurses in this study were taught on proper instillation of eye drops and at scheduled intervals as per our study protocol. Manzoni et al observed that birth by vaginal delivery was an independent predictor of threshold ROP compared with caesarean section in extremely low birth weight infants $(\mathrm{p}=0.04) .{ }^{46}$ Kardum et al did not find significant difference in the rate of ROP between babies born vaginally compared with caesarean section. ${ }^{47}$ Caesarean section as a mode of delivery of babies was associated with a reduced risk of ROP in this current study (aHR 0.3, $\mathrm{p}=0.019$ ).

There are several limitations to our study. Due to the high mortality among the extremely premature babies, the incidence of ROP among babies with GA $<27$ weeks could not be determined. Also, 19\% of eligible babies could not be examined either due to early discharge of the babies without being referred for eye examination, transfer out of the NICU prior to eye examination or parents revoking consent. Aside poor pupillary dilation, other factors were not significantly associated with type 1 ROP probably due to the small number of babies who developed these conditions. The duration of oxygen use was excluded from statistical analysis due to poor documentation of this parameter. Although the sample size for this study is small compared with studies outside Africa, it is the largest single centre prospective study on ROP in West Africa, and has provided risk factors that influence the incidence of ROP in a West African population.

In conclusion, the cumulative incidence of ROP at the NICU of KBTH was $13.7 \%$ and type 1 ROP occurred in babies with birth weight less than $1250 \mathrm{~g}$. The independent risk factors for ROP in these Ghanaian premature 
infants were very low birth weight, exposure to supplemental oxygen, confirmed sepsis, feeding via nasogastric tube and poor pupillary dilatation. Male sex and delivery via caesarean section were associated with reduced risk of ROP. We recommend routine screening of infants with birth weight less than $1.6 \mathrm{~kg}$ or gestational age less than or equal to 34 weeks for ROP in Ghana. Further studies are required to establish more robust screening criteria for ROP in Ghana. A large multicentre study on risk factors for ROP is urgently required in Ghana and sub-Saharan Africa.

\section{Author affiliations}

${ }^{1}$ Surgery (Eye), University of Ghana Medical School, College of Health Sciences, Accra, Ghana

${ }^{2}$ Lions International Eye Centre, Korle Bu Teaching Hospital, Accra, Ghana

${ }^{3}$ Child Health, University of Ghana Medical School, College of Health Sciences, Accra, Ghana

${ }^{4}$ Child Health, Korle Bu Teaching Hospital, Accra, Ghana

${ }^{5}$ Epidemiology, School of Public health, University of Ghana College of Health Sciences, Accra, Ghana

${ }^{6}$ Bio-statistics, School of Public Health, University of Ghana College of Health Sciences, Accra, Ghana

Acknowledgements We are grateful to the staff of the NICU in Korle-Bu Teaching Hospital (KBTH) and the pediatric unit of the Eye Department of KBTH for assisting with patient recruitment and examinations. We thank Dr Aeesha Malik and Professor Claire Gilbert of the London School of Hygiene and Tropical Medicine for their support during the conduct of this study.

Contributors Study concept and design (IZB, CE-L, AHS, VAE, EK), conduct of study (IZB, VAE, I-OD-BO-A, VB, AO), retrieval and analysis of data (IZB, KA), data interpretation (IZB, KA), preparation of manuscript (IZB, KA), critical review of manuscript (IZB, CE-L, AHS, EK, KA, I-OD-BO-A, VB, AO, VAE), approval of manuscript (IZB, CE-L, AHS, EK, KA, I-OD-BO-A, VB, AO, VAE) and accountable for all aspects of the work (IZB, CE-L, AHS, EK, KA, I-OD-BO-A, VB, AO, VAE).

Funding This study received financial support from Korle-Bu Teaching Hospital (KBTH) operational research fund. KBTH had no role in study design, data collection and analysis, decision to publish or preparation of the manuscript.

Competing interests None declared.

Patient consent for publication Informed consent was obtained from parents of all infants enrolled in the study.

Ethics approval The study was approved by the Korle-Bu Teaching Hospital Institutional Review Board (KBTH/RB/00085/2017).

Provenance and peer review Not commissioned; externally peer reviewed.

Data availability statement Data are available in a public, open access repository. Data set available from the Dryad repository https://datadryad.org/stash/share/ RJheTCPIplgnn9PugUokTjd0876F02AAmVwh3t4Dtl8

Open access This is an open access article distributed in accordance with the Creative Commons Attribution Non Commercial (CC BY-NC 4.0) license, which permits others to distribute, remix, adapt, build upon this work non-commercially, and license their derivative works on different terms, provided the original work is properly cited, appropriate credit is given, any changes made indicated, and the use is non-commercial. See: http://creativecommons.org/licenses/by-nc/4.0/.

\section{ORCID iD}

Imoro Zeba Braimah http://orcid.org/0000-0002-2573-9026

\section{REFERENCES}

1 Blencowe H, Lawn JE, Vazquez T, et al. Preterm-associated visual impairment and estimates of retinopathy of prematurity at regional and global levels for 2010. Pediatr Res 2013;74 Suppl 1:35-49.

2 Gilbert C. Retinopathy of prematurity: a global perspective of the epidemics, population of babies at risk and implications for control. Early Hum Dev 2008;84:77-82.
3 Darlow BA, Gilbert CE, Quiroga AM. Setting up and improving retinopathy of prematurity programs: interaction of neonatology, nursing, and ophthalmology. Clin Perinatol 2013;40:215-27.

4 Fierson WM, American Academy of Pediatrics Section on Ophthalmology, American Academy of Ophthalmology. Screening examination of premature infants for retinopathy of prematurity. Pediatrics 2013;131:189-95.

5 Fleck BW, Stenson BJ. Retinopathy of prematurity and the oxygen conundrum: lessons learned from recent randomized trials. Clin Perinatol 2013;40:229-40.

6 Good WV, Early Treatment for Retinopathy of Prematurity Cooperative Group. Final results of the early treatment for retinopathy of prematurity (ETROP) randomized trial. Trans Am Ophthalmol Soc 2004;102:233-48.

7 Sanghi G, Dogra MR, Das P, et al. Aggressive posterior retinopathy of prematurity in Asian Indian babies: spectrum of disease and outcome after laser treatment. Retina 2009;29:1335-9.

8 Early Treatment For Retinopathy Of Prematurity Cooperative Group. Revised indications for the treatment of retinopathy of prematurity: results of the early treatment for retinopathy of prematurity randomized trial. Arch Ophthalmol 2003;121:1684-94.

9 Fielder AR. Preliminary results of treatment of eyes with high-risk prethreshold retinopathy of prematurity in the early treatment for retinopathy of prematurity randomized trial. Arch Ophthalmol 2003;121:1769-71.

10 Slidsborg C, Jensen A, Forman JL, et al. Neonatal risk factors for treatment-demanding retinopathy of prematurity: a Danish national study. Ophthalmology 2016;123:796-803.

11 Husain SM, Sinha AK, Bunce C, et al. Relationships between maternal ethnicity, gestational age, birth weight, weight gain, and severe retinopathy of prematurity. J Pediatr 2013;163:67-72.

12 Sabri K, Manktelow B, Anwar S, et al. Ethnic variations in the incidence and outcome of severe retinopathy of prematurity. Can $\mathrm{J}$ Ophthalmol 2007;42:727-30.

13 Saunders RA, Donahue ML, Christmann LM, et al. Racial variation in retinopathy of prematurity. The cryotherapy for retinopathy of prematurity cooperative group. Arch Ophthalmol 1997;115:604-8.

14 Wu C, Vanderveen DK, Hellström A, et al. Longitudinal postnatal weight measurements for the prediction of retinopathy of prematurity. Arch Ophthalmol 2010;128:443-7.

15 Shah PK, Narendran V, Kalpana N. Aggressive posterior retinopathy of prematurity in large preterm babies in South India. Arch Dis Child Fetal Neonatal Ed 2012;97:F371-5.

16 UNICEF. Monitoring the situation of children and women, 2017. Available: https://data.unicef.org/country/gha

17 Hug L, Alexander M, You D, et al. National, regional, and global levels and trends in neonatal mortality between 1990 and 2017, with scenario-based projections to 2030: a systematic analysis. Lancet Glob Health 2019;7:e710-20.

18 Enweronu-Laryea CC, Nkyekyer K, Rodrigues OP. The impact of improved neonatal intensive care facilities on referral pattern and outcome at a teaching hospital in Ghana. J Perinatol 2008;28:561-5.

19 Sackey AH, Tagoe LG. Admissions and mortality over a 5-year period in a limited-resource neonatal unit in Ghana. Ghana Med $J$ 2019;53:117-25.

20 Ballard JL, Khoury JC, Wedig K, et al. New Ballard score, expanded to include extremely premature infants. J Pediatr 1991;119:417-23.

21 International Committee for the Classification of Retinopathy of Prematurity. The international classification of retinopathy of prematurity revisited. Arch Ophthalmol 2005;123:991-9.

22 Baiyeroju-Agbeja AM, Omokhodion SI. Screening for retinopathy of prematurity in Ibadan. Nigerian J Ophthalmol 1998;6:23-5.

23 Ademola-Popoola D, Adesiyun O, Durotoye IA, et al. Screening programme for retinopathy of prematurity in Ilorin, Nigeria: a pilot study. West Afr J Med 2013;32:281-5.

24 Adio AO, Ugwu RO, Nwokocha CG, et al. Retinopathy of prematurity in Port harcourt, Nigeria. ISRN Ophthalmol 2014;2014:1-6.

25 Gilbert C, Fielder A, Gordillo L, et al. Characteristics of infants with severe retinopathy of prematurity in countries with low, moderate, and high levels of development: implications for screening programs. Pediatrics 2005;115:e518-25.

26 Jalali S, Matalia J, Hussain A, et al. Modification of screening criteria for retinopathy of prematurity in India and other middle-income countries. Am J Ophthalmol 2006;141:966-8.

27 Zin AA, Moreira MEL, Bunce C, et al. Retinopathy of prematurity in 7 neonatal units in Rio de Janeiro: screening criteria and workload implications. Pediatrics 2010;126:e410-7.

28 Mayet I, Cockinos C. Retinopathy of prematurity in South Africans at a tertiary hospital: a prospective study. Eye 2006;20:29-31. 
29 Freitas AM, Mörschbächer R, Thorell MR, et al. Incidence and risk factors for retinopathy of prematurity: a retrospective cohort study. Int J Retina Vitreous 2018;4:20.

30 Wanjala I, llako D, Kariuki L. Retinopathy of prematurity as seen in two major hospitals. East Afr J Ophthalmol 2007;13:5-14.

31 Jacoby MR, Du Toit L. Screening for retinopathy of prematurity in a provincial hospital in Port Elizabeth, South Africa. S Afr Med J 2016;106:SAMJ.2016.v106i6.10663.

32 Onyango O, Sitati S, Amolo L, et al. Retinopathy of prematurity in Kenya: prevalence and risk factors in a hospital with advanced neonatal care. Pan Afr Med J 2018;29:152.

33 Global, regional, GBD 2015 Child Mortality Collaborators. Global, regional, national, and selected subnational levels of stillbirths, neonatal, infant, and under-5 mortality, 1980-2015: a systematic analysis for the global burden of disease study 2015. Lancet 2016;388:1725-74.

34 Hadi AMA, Hamdy IS. Correlation between risk factors during the neonatal period and appearance of retinopathy of prematurity in preterm infants in neonatal intensive care units in Alexandria, Egypt. Clin Ophthalmol 2013;7:831-7.

35 Fierson WM, AMERICAN ACADEMY OF PEDIATRICS Section on Ophthalmology, AMERICAN ACADEMY OF OPHTHALMOLOGY. Screening examination of premature infants for retinopathy of prematurity. Pediatrics 2018;142:e20183061.

36 Wilkinson AR, Haines L, Head K, et al. Uk retinopathy of prematurity guideline. Eye 2009;23:2137-9.

37 van Sorge AJ, Termote JUM, Kerkhoff FT, et al. Nationwide inventory of risk factors for retinopathy of prematurity in the Netherlands. $J$ Pediatr 2014;164:494-8.
38 Ludwig CA, Chen TA, Hernandez-Boussard T, et al. The epidemiology of retinopathy of prematurity in the United States. Ophthalmic Surg Lasers Imaging Retina 2017;48:553-62.

39 Fajolu IB, Rotimi-Samuel A, Aribaba OT, et al. Retinopathy of prematurity and associated factors in Lagos, Nigeria. Paediatr Int Child Health 2015;35:324-8

40 Darlow BA, Hutchinson JL, Henderson-Smart DJ, et al. Prenatal risk factors for severe retinopathy of prematurity among very preterm infants of the Australian and New Zealand neonatal network. Pediatrics 2005:115:990-6.

41 Nødgaard $\mathrm{H}$, Andreasen $\mathrm{H}$, Hansen $\mathrm{H}$, et al. Risk factors associated with retinopathy of prematurity $(\mathrm{ROP})$ in northern Jutland, Denmark 1990-1993. Acta Ophthalmol Scand 1996;74:306-10.

42 Shim S-Y, Cho SJ, Kong KA, et al. Gestational age-specific sex difference in mortality and morbidities of preterm infants: a nationwide study. Sci Rep 2017;7:6161.

43 Stevenson DK, Verter J, Fanaroff AA, et al. Sex differences in outcomes of very low birthweight infants: the newborn male disadvantage. Arch Dis Child Fetal Neonatal;3:182-5.

44 Weng Y-H, Yang C-Y, Chiu Y-W. Neonatal outcomes in relation to sex differences: a national cohort survey in Taiwan. Biol Sex Differ 2015;6:30.

45 Mizuno K, Ueda A. The maturation and coordination of sucking, swallowing, and respiration in preterm infants. $J$ Pediatr 2003;142:36-40.

46 Manzoni P, Farina D, Maestri A, et al. Mode of delivery and threshold retinopathy of prematurity in pre-term ELBW neonates. Acta Paediatr 2007;96:221-6.

47 Kardum D, GRCIC BF, Muller A, et al. Outcomes of very low birth weight infants born by vaginal delivery versus cesarean section. Signa Vitae 2018;14:46-50. 